\title{
Awareness on Usage of Skeletal Muscle Relaxants in Dental Practice Among Dental Students
}

\author{
Inchara . ${ }^{1}$, Dhanraj Ganapathy ${ }^{2}$, Subhashree $\mathrm{R}^{3}$ and Rakshagan $\mathrm{V}^{4}$ \\ ${ }^{1}$ Department of Prosthodontics Saveetha Dental College And Hospitals Saveetha \\ Institute of Medical And Technical Sciences Saveetha University Chennai. \\ ${ }^{2}$ Professor and HOD Department of Prosthodontics Saveetha Dental College And Hospitals \\ Saveetha Institute of Medical And Technical Sciences Saveetha University Chennai, India \\ ${ }^{3}$ Senior Lecturer Department of Prosthodontics Saveetha Dental College and Hospitals Saveetha \\ Institute of Medical and Technical Sciences Saveetha University Chennai -77, India \\ ${ }^{4}$ Senior Lecturer Department of Prosthodontics Saveetha Dental College and Hospitals Saveetha \\ Institute of Medical and Technical Sciences Saveetha University Chennai -77, India
}

\section{ABSTRACT}

A muscle relaxant is a drug that affects skeletal muscle function and decreases the muscle tone.it may be used to alleviate symptoms such as muscle spasm, pain, and hyperreflexia. Muscle relaxants in dentistry are often used in treating temporomandibular joint disorders.Temporomandibular disorders result from musculoskeletal dysfunction of the orofacial region affecting masticatory muscles, temporomandibular joints, and associated structures. The aim of the study is to Evaluate awareness on usuage of skeletal muscle relaxants in dental practise among dental students. A set of questionnaire was framed and online survey was conducted among 100 dental students. The answers given by dental students were collected and the use of skeletal muscle relaxants in dental practise was determined. And the results were statistically analysed. The results showed that many dental students were not aware of proper usage of SMRs in the field of dentistry. Baclofen was the most common skeletal muscle relaxant prescribed and the common reason for prescription of skeletal muscle relaxant was TMJ disorder. It is concluded that it is important to create awareness on usage of skeletal muscle relaxants which includes the dosage, methods of administration, advantages and disadvantages.

\section{KEY WORDS: DENTAL STUDENTS; DENTISTRY; SKELETAL MUSCLE RELAXANTS; TMJ DISORDERS.}

\section{INTRODUCTION}

Skeletal muscle relaxants are a diverse group of medications that are not chemically related like other drug classes and work through a variety of mechanisms.(See

\section{ARTICLE INFORMATION}

*Corresponding Author: dhanraj@saveetha.com

Received 17th June 2020 Accepted after revision 12th August 2020 Print ISSN: 0974-6455 Online ISSN: 2321-4007 CODEN: BBRCBA

Thomson Reuters ISI Web of Science Clarivate Analytics USA and Crossref Indexed Journal

$$
\text { 1) Clarivate }{ }_{\text {Analytics }}
$$

NAAS Journal Score 2020 (4.31) SJIF: 2020 (7.728)

A Society of Science and Nature Publication,

Bhopal India 2020. All rights reserved.

Online Contents Available at: http//www.bbrc.in/

Doi: http://dx.doi.org/10.21786/bbrc/13.7/12 and Ginzburg, 2008) The term "muscle relaxant" is used to refer to two major therapeutic groups: neuromuscular blockers and spasmolytics.(Witenko et al., 2014) They can further be divided into antispastic and antispasmodic medications and are used for different indications.(Dillon et al., 2004) Since these drugs primarily work through the central nervous system, they have accompanying adverse effects such as sedation and dizziness that may limit their use.(Chou, 2010) The antispasticity agentsbaclofen, tizanidine, dantrolene, and diazepam-aid in improving muscle hypertonicity and involuntary jerks. Antispasmodic agents, such as cyclobenzaprine, are primarily used to treat musculoskeletal conditions. (See and Ginzburg, 2008; Ledowski et al., 2018)

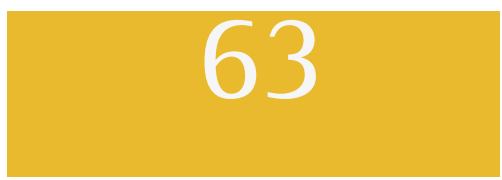


In general, antispasticity agents and antispasmodics are not interchangeable and should not be substituted for one another.(Chisholm-Burns et al., 2019) Limited evidence exists for comparing one agent with another, so selecting an optimal agent relies on important patientspecific factors such as risks for side effects, potential drug interactions with concomitant therapies, and total cost.(Shaheed et al., 2017)

Common musculoskeletal conditions causing tenderness and muscle spasms include fibromyalgia, tension headaches, myofascial pain syndrome, and mechanical low back or neck pain.(Beebe, Barkin and Barkin, 2005) If muscle spasm is present in these conditions, it is related to local factors involving affected muscle groups.(Moody, Fu and Fang, 2018) These conditions are commonly encountered in clinical practice and can cause significant disability and pain in some patients. Skeletal muscle relaxants are one of several classes of medications frequently used to treat these conditions. (Kumbham, Ghate and Lewis, 2019)

Muscle strains and other musculoskeletal disorders (MSDs) are a leading cause of work absenteeism. Muscle pain, spasm, swelling, and inflammation are symptomatic of strains. The precise relationship between musculoskeletal pain and spasm is not well understood. Temporomandibular disorders (TMD) result from musculoskeletal dysfunction of the orofacial region affecting masticatory muscles, temporomandibular joints (TMJ), and other associated structures. The main characteristics of these problems are facial and TMJ pain, headache, earache, dizziness, masticatory muscle hypertrophy, limited mouth opening, locked jaw, abnormal teeth wear, joint sounds, and others.The muscle relaxants used in treating temporomandibular disorders are carisoprodol, cyclobenzaprine, diazepam, metaxalone, alprazolam and tizanidine. Diazepam appears to reduce spasticity by enhancing the inhibitory effects of neurotransmitter GABA(Gonzalez et al., 2009)

In general, muscle relaxants are controversial alternatives that have efficacy in nonspecific back pain but carry risks of adverse effects and increased cost.(Li et al., 2020) Much of the evidence from clinical trials regarding skeletal muscle relaxants is limited because of poor methodologic design, insensitive assessment methods, and small numbers of patients.(Reeves and Burke, 2010; Lumba-Brown et al., 2018) Recent literature analyzing the prevalence of muscle relaxant use is scarce. Some clinicians would agree that the medications in this class tend to be used more frequently than necessary, but clear data is lacking.(Trueman, Castillo and Hoie, 2020) All clinicians should be fully aware of the recent trends in their speciality to enable them to provide effective and successful treatment to their patients. This study aims at evaluating the awareness on usage of skeletal muscle relaxants in dental practice among dental students.

Previously our team had conducted numerous clinical trials(Ganapathy et al., 2016; Selvan and Ganapathy, 2016; Subasree, Murthykumar and Others, 2016; Jyothi et al., 2017; Ranganathan, Ganapathy and Jain, 2017; Duraisamy et al., 2019; Jain, Nallaswamy and Ariga, 2019), lab animal studies(Ashok et al., 2014; Venugopalan et al., 2014; Ashok and Suvitha, 2016; Ganapathy et al., 2016; Vijayalakshmi and Ganapathy, 2016) and in-vitro studies(Ajay et al., 2017; Basha, Ganapathy and Venugopalan, 2018; Kannan and Venugopalan, 2018) over the past 5 years. Now we are focussing on epidemiological surveys. The idea for this survey stemmed from the current interest in our community.

\section{MATERIAL AND METHODS}

This research was conducted in Saveetha dental college and hospitals, Chennai. The data collection included standardized questionnaires consisting of 8 questions. The online survey using surveyplanet was conducted among 100 dental students. The questions were based on knowledge of usage, prescription, common skeletal muscle relaxant used, reason for prescription, calculation of dosage, side effects, combination of other drugs, and route of administration of skeletal muscle relaxants in dental practice among dental students. The responses were collected and analysed for statistical differences. The questionnaire and the response collected was represented in the form of pie charts.

\section{RESULTS AND DISCUSSION}

According to the study results, around $63.64 \%$ of dental students were not aware of usage of skeletal muscle relaxants in the field of dentistry (FIGURE 1). Out of 100 dental students $85 \%$ of them had not prescribed any skeletal muscle relaxants in dental practice (FIGURE 2). Baclofen (53.54\%) was the most commonly prescribed skeletal muscle relaxant, followed by dantrolene (36.36\%) (FIGURE 3). TMJ disorder( 69.70\%) was the most common reason for prescription of skeletal muscle relaxants followed by anxiety (15.15\%) (FIGURE 4). Around 59.60\% of dental students calculated the dosage of the drug based on age of patients and 23.23\% of them calculated the dosage based on gender and 17.17\% calculated the dosage based on body weight of the patient (FIGURE 5). 43.43\% of dental students were aware of the side effects of the skeletal muscle relaxants and 56.57\% of dental students were not aware of the side effects associated with skeletal muscle relaxants (FIGURE 6). In FIGURE 7, 37.37\% of dental students were aware of using skeletal muscle relaxants in combination with other drugs and $62.63 \%$ of dental students were not aware of using skeletal muscle relaxants in combination with other drugs. In FIGURE 8, 58.59\% dental students preferred the intravenous route of administration , 26.26\% preferred the intramuscular route of administration while $15.15 \%$ of dental students preferred oral route of administration of skeletal muscle relaxants (FIGURE 8).

Skeletal muscle relaxants are used medically as adjuncts to rest, physical therapy, and other measures for the relief of discomfort associated with acute, painful musculoskeletal conditions.Most clinical guidelines list skeletal muscle relaxants as optional agents for use 
individually or in combination with an NSAID. The Agency for Health Care Policy and Research (AHCPR) guidelines, published in 1995, specifically noted that skeletal muscle relaxants alone or in combination with an NSAID are no more effective than using an NSAID alone.(Hersh, Balasubramaniam and Pinto, 2008) In study conducted by Eric chang et al.,Baclofen is considered the first-line treatment for spasticity.(Chang et al., 2013) Moreover, in study conducted by Hermanet al., cyclobenzaprine was superior to placebo or $0.5 \mathrm{mg}$ clonazepam when added to self-care and education in the management of TMD.(Herman et al., 2002).

Figure 1: Pie chart depicting the knowledge among dental students regarding the use of skeletal muscle relaxants in the field of dentistry.The blue colour depicts that the participants were aware of usage of skeletal muscle relaxants in the field of dentistry and black colour denotes that that the participants were not aware of usage of skeletal muscle relaxants in the field of dentistry.

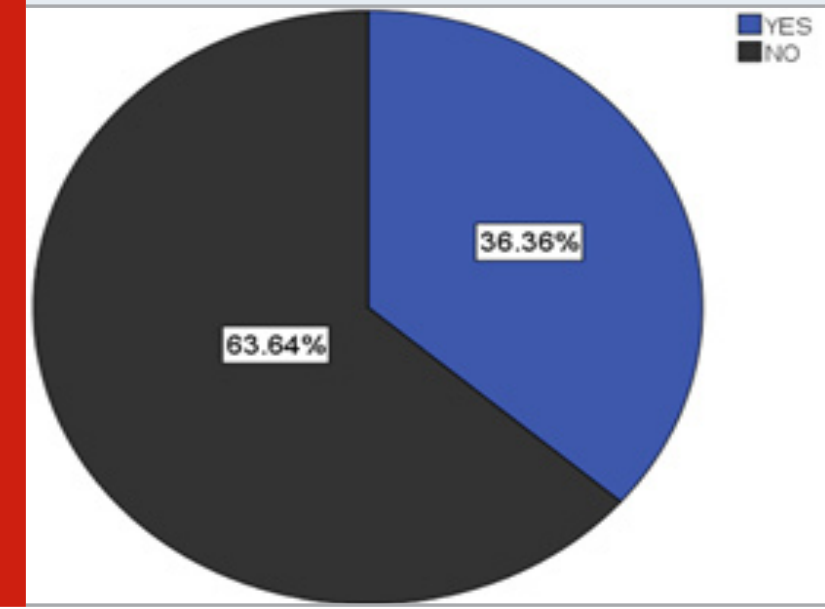

Figure 2: Pie chart depicting the responses regarding the prescription of skeletal muscle relaxants in the field of dentistry by dental students. The blue colour denotes that around $15.0 \%$ of the dental students had prescribed the skeletal muscle relaxants and the black colour denotes that around $85 \%$ of dental students have not prescribed any skeletal muscle relaxants in dental practice.

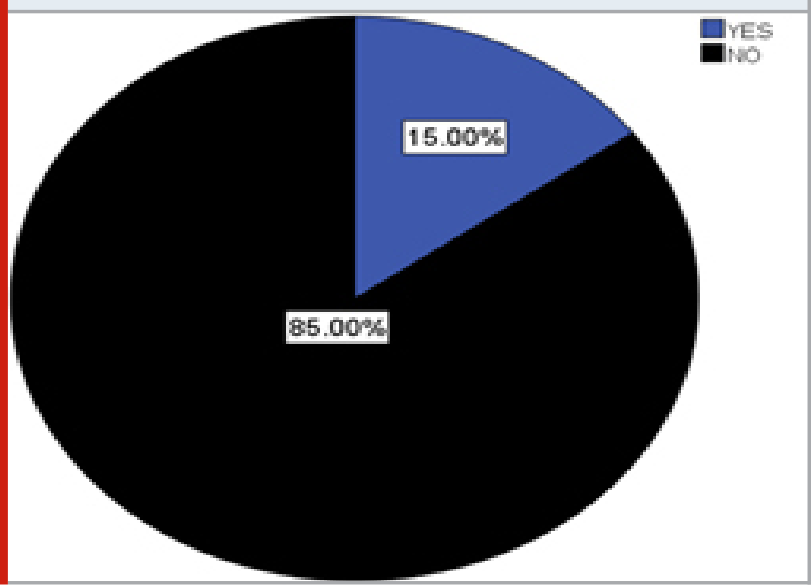

Figure 3: Pie chart depicting the common skeletal muscle relaxants prescribed by the dental students. The blue colour denotes 53.54\% prescribed baclofen, green denotes that $36.36 \%$ prescribed dantrolene,light brown denotes 4.04\% prescribed cyclobenzaprine, purple denotes 3.03\% prescribed chlorzoxazone and yellow denotes $3.03 \%$ prescribed other skeletal muscle relaxants.

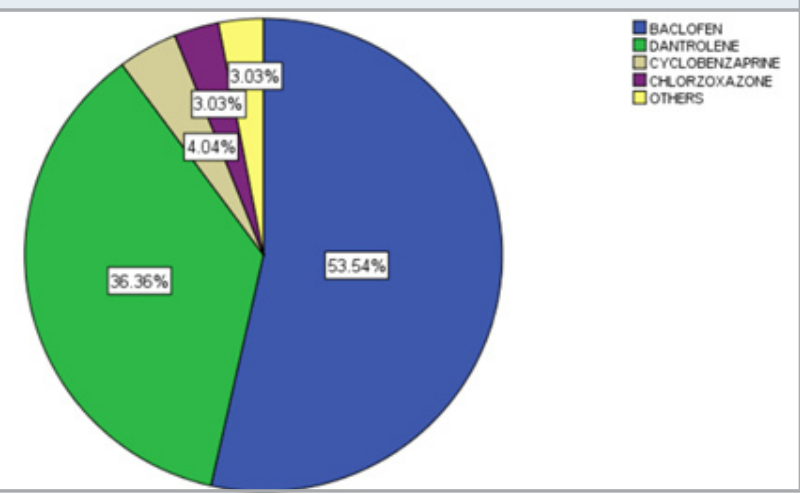

Figure 4: Pie chart depicting the common reasons for prescription of skeletal muscle relaxants in the field of dentistry by dental students. The blue denotes TMJ disorder (69.70\%), green denotes anxiety (15.15\%), light brown denotes bruxism (8.08\%), purple denotes sedation(7.07\%).

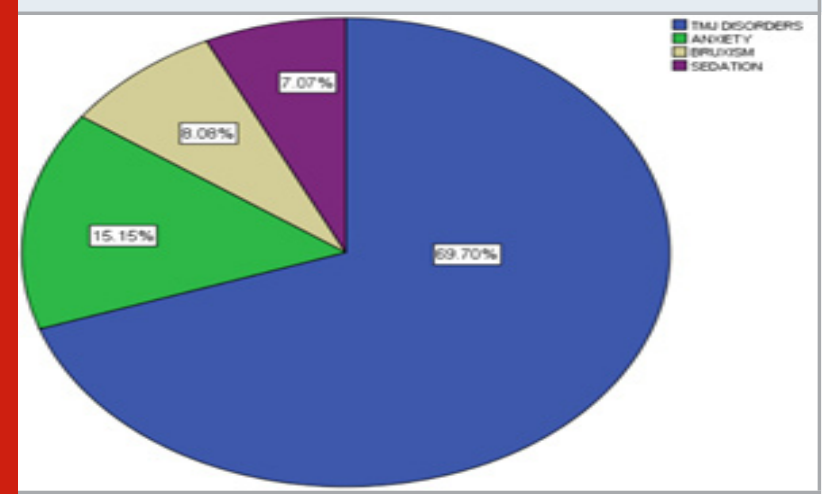

Figure 5: Pie chart depicting the calculation of dosage of skeletal muscle relaxants prescribed by dental students in the field of dental practice. The blue denotes age (59.06\%), green denotes gender(23.23\%), light brown denotes the body weight (17.17\%).

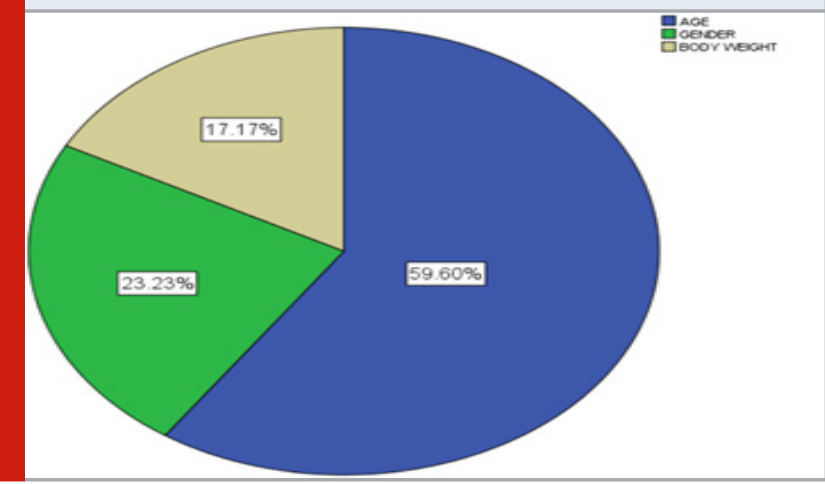


Figure 6: Pie chart depicting the knowledge of side effects of skeletal muscle relaxants among dental students. The blue denotes that $43.43 \%$ dental students were aware of side effects and black denotes that $56.57 \%$ were not aware of side effects of skeletal muscle relaxant

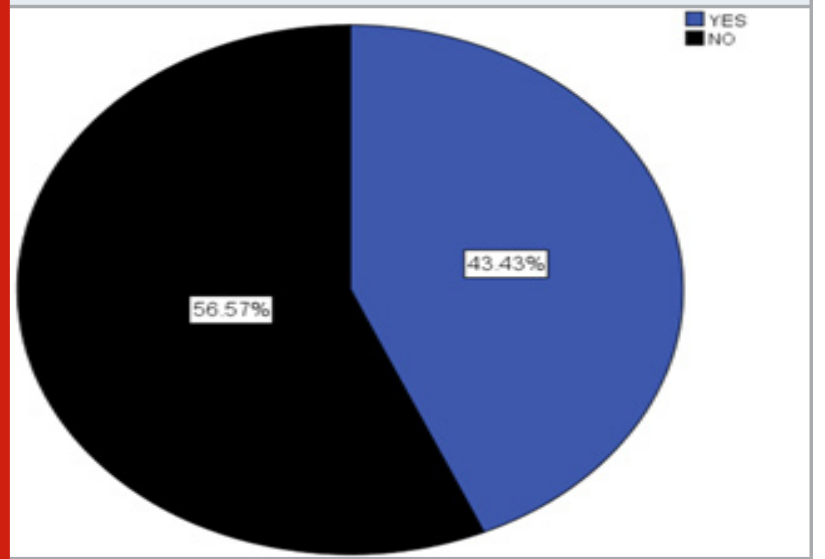

Figure 7: Pie chart depicting the knowledge of dental students about prescription of skeletal muscle relaxants in combination with other drugs. The blue denotes that $37.37 \%$ were aware of prescribing skeletal muscle relaxants in combination with other drugs. The black denotes $62.63 \%$ were not aware of prescribing skeletal muscle relaxants in combination with other drugs

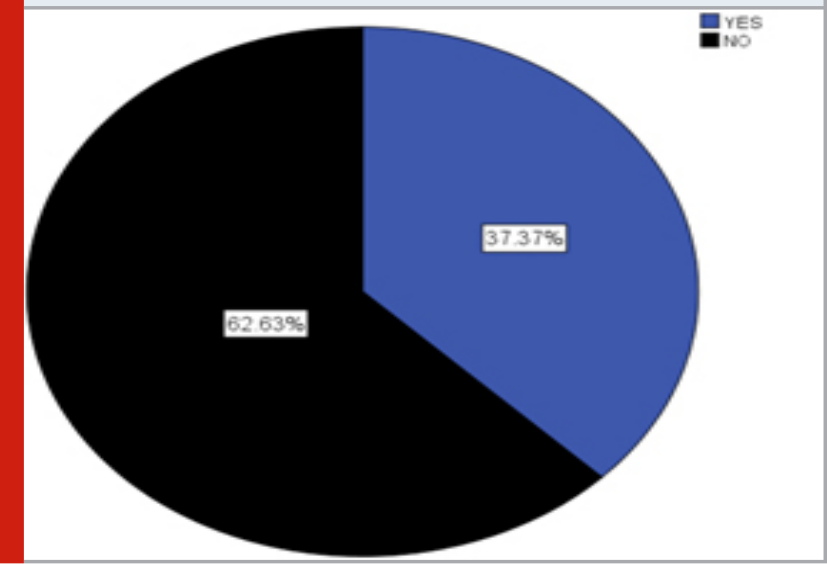

Figure 8: Pie chart depicting the mode of administration of skeletal muscle relaxants in the field of dentistry among dental students. The blue denotes intravenous route of administration (58.595), green denotes oral route of administration (15.15\%), light brown denotes intramuscular route of administration (26.26\%).

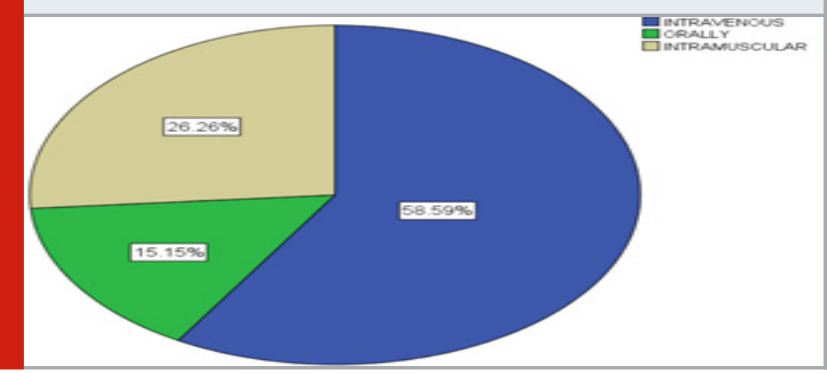

66
Muscle relaxants can be addictive for some people. Taking them without a prescription, or taking more than your doctor has recommended, can increase chances of becoming addicted. (Kobayashi, Hasegawa and Ono, 1996) Risk of hepatic injury appears to be greater in females, in patients $>35$ years of age, and in patients taking other medications in addition to dantrolene. (Waldman, 2009) In the study conducted by sharmila et al., Muscle relaxants are commonly indicated for the treatment of Treatment of TMJ disorders.(Sharmila, no date) One vital aspect of the treatment is that the clinician should constantly update his knowledge on the drugs being administered during the course of treatment and their interactions.

\section{CONCLUSION}

Within the study limits, it was concluded that the majority of dental students were not aware of usage of skeletal muscle relaxants in the field of dentistry. The risk of adverse drug events raises concern for their safety in routine use. Hence it is important to create awareness on usage of skeletal muscle relaxants which includes the dosage, methods of administration, advantages and disadvantages for better understanding of prescribing medications.

\section{ACKNOWLEDGEMENTS}

We would like to acknowledge Saveetha dental college and hospitals for giving an opportunity to conduct this research and also we would thank all the participants who took part in this study.

\section{Conflict of Interest}

The author declares no conflict of interest.

\section{REFERENCES}

Ajay, R. et al. (2017) 'Effect of Surface Modifications on the Retention of Cement-retained Implant Crowns under Fatigue Loads: An In vitro Study', Journal of pharmacy At bioallied sciences, 9(Suppl 1), pp. S154-S160.

Ashok, V. et al. (2014) 'Lip Bumper Prosthesis for an Acromegaly Patient: A Clinical Report', Journal of Indian Prosthodontic Society, 14(Suppl 1), pp. 279282.

Ashok, V. and Suvitha, S. (2016) 'Awareness of all ceramic restoration in rural population', Research Journal of Pharmacy and Technology. A \& V Publications, 9(10), pp. 1691-1693.

Basha, F. Y. S., Ganapathy, D. and Venugopalan, S. (2018) 'Oral Hygiene Status among Pregnant Women', Research Journal of Pharmacy and Technology, p. 3099. doi: 10.5958/0974-360x.2018.00569.3.

Beebe, F. A., Barkin, R. L. and Barkin, S. (2005) 'A clinical and pharmacologic review of skeletal muscle relaxants for musculoskeletal conditions', American journal of therapeutics, 12(2), pp. 151-171. 
Chang, E. et al. (2013) 'A Review of Spasticity Treatments: Pharmacological and Interventional Approaches', Critical reviews in physical and rehabilitation medicine, 25(1-2), pp. 11-22.

Chisholm-Burns, M. A. et al. (2019) Pharmacotherapy Principles and Practice, Fifth Edition. McGraw Hill Professional.

Chou, R. (2010) 'Pharmacological management of low back pain', Drugs, 70(4), pp. 387-402.

Dillon, C. et al. (2004) 'Skeletal muscle relaxant use in the United States: data from the Third National Health and Nutrition Examination Survey (NHANES III)', Spine, 29(8), pp. 892-896.

Duraisamy, R. et al. (2019) 'Compatibility of Nonoriginal Abutments With Implants: Evaluation of Microgap at the Implant-Abutment Interface, With Original and Nonoriginal Abutments', Implant dentistry, 28(3), pp. 289-295.

Ganapathy, D. et al. (2016) 'Effect of Resin Bonded Luting Agents Influencing Marginal Discrepancy in All Ceramic Complete Veneer Crowns', Journal of clinical and diagnostic research: JCDR, 10(12), pp. ZC67-ZC70.

Gonzalez, L. A. et al. (2009) 'Carisoprodol-mediated modulation of GABAA receptors: in vitro and in vivo studies', The Journal of pharmacology and experimental therapeutics, 329(2), pp. 827-837.

Herman, C. R. et al. (2002) 'The effectiveness of adding pharmacologic treatment with clonazepam or cyclobenzaprine to patient education and self-care for the treatment of jaw pain upon awakening: a randomized clinical trial', Journal of orofacial pain, 16(1), pp. 64-70.

Hersh, E. V., Balasubramaniam, R. and Pinto, A. (2008) 'Pharmacologic management of temporomandibular disorders', Oral and maxillofacial surgery clinics of North America, 20(2), pp. 197-210, vi.

Jain, A. R., Nallaswamy, D. and Ariga, P. (2019) 'Determination of Correlation of Width of Maxillary Anterior Teeth with Extraoral Factor (Interpupillary Width) in Indian Population', Journal of clinical and diagnostic research. doi: 10.7860/jcdr/2019/41082.12988.

Jyothi, S. et al. (2017) 'Periodontal health status of three different groups wearing temporary partial denture', Research Journal of Pharmacy and Technology. A \& V Publications, 10(12), pp. 4339-4342.

Kannan, A. and Venugopalan, S. (2018) 'A systematic review on the effect of use of impregnated retraction cords on gingiva', Research Journal of Pharmacy and Technology. A \& V Publications, 11(5), pp. 21212126.

Kobayashi, H., Hasegawa, Y. and Ono, H. (1996) 'Cyclobenzaprine, a centrally acting muscle relaxant, acts on descending serotonergic systems', European journal of pharmacology, 311(1), pp. 29-35.

Kumbham, S., Ghate, V. and Lewis, S. A. (2019) 'Approaches for the delivery of skeletal muscle relaxants: A review', Indian Drugs. Indian Drug Manufacturers' Association, 56(7), pp. 7-15.

Ledowski, T. et al. (2018) 'Effects of muscle relaxants on ischaemia damage in skeletal muscle', Scientific reports, 8(1), p. 5794.

Li, Y. et al. (2020) 'Risk of Opioid Overdose Associated With Concomitant Use of Opioids and Skeletal Muscle Relaxants: A Population-Based Cohort Study', Clinical pharmacology and therapeutics, 108(1), pp. 81-89.

Lumba-Brown, A. et al. (2018) 'Centers for Disease Control and Prevention Guideline on the Diagnosis and Management of Mild Traumatic Brain Injury Among Children', JAMA pediatrics. American Medical Association, 172(11), pp. e182853-e182853.

Moody, D. E., Fu, Y. and Fang, W. B. (2018) 'Inhibition of In Vitro Metabolism of Opioids by Skeletal Muscle Relaxants', Basic \&t clinical pharmacology \&t toxicology, 123(3), pp. 327-334.

Ranganathan, H., Ganapathy, D. M. and Jain, A. R. (2017) 'Cervical and Incisal Marginal Discrepancy in Ceramic Laminate Veneering Materials: A SEM Analysis', Contemporary clinical dentistry, 8(2), pp. 272-278.

Reeves, R. R. and Burke, R. S. (2010) 'Carisoprodol: abuse potential and withdrawal syndrome', Current drug abuse reviews, 3(1), pp. 33-38.

See, S. and Ginzburg, R. (2008) 'Skeletal muscle relaxants', Pharmacotherapy, 28(2), pp. 207-213.

Selvan, S. R. and Ganapathy, D. (2016) 'Efficacy of fifth generation cephalosporins against methicillin-resistant Staphylococcus aureus-A review', Research Journal of Pharmacy and Technology. A \& V Publications, 9(10), pp. 1815-1818.

Shaheed, C. A. et al. (2017) 'Efficacy and tolerability of muscle relaxants for low back pain: Systematic review and meta-analysis', European Journal of Pain, pp. 228-237. doi: 10.1002/ejp.907.

Sharmila, R. (no date) 'Muscle Relaxants in Treating Tempromandibular Joint Disorder- An Update'. Available at: https://www.jpsr.pharmainfo.in/Documents/ Volumes/vol7Issue08/jpsr07081530.pdf.

Subasree, S., Murthykumar, K. and Others (2016) 'Effect of Aloe Vera in Oral Health-A Review', Research Journal of Pharmacy and Technology. A \& V Publications, 9(5), pp. 609-612.

Trueman, C., Castillo, S. and Hoie, E. (2020) 'Inappropriate Use of Skeletal Muscle Relaxants in Geriatric Patients', U. S. pharmacist, 45(1), pp. 25-29.

Venugopalan, S. et al. (2014) 'Case Report: Magnetically 
retained silicone facial prosthesis', Nigerian journal of clinical practice, 17(2), pp. 260-264.

Vijayalakshmi, B. and Ganapathy, D. (2016) 'Medical management of cellulitis', Research Journal of Pharmacy and Technology. A \&t V Publications, 9(11), pp. 2067-2070.

Waldman, S. D. (2009) ‘Skeletal Muscle Relaxants', Pain
Review, pp. 651-656. doi: 10.1016/b978-1-4160-58939.00347-6.

Witenko, C. et al. (2014) 'Considerations for the appropriate use of skeletal muscle relaxants for the management of acute low back pain', P \& T: a peerreviewed journal for formulary management, 39(6), pp. 427-435. 